\title{
Debris flow impact assessment along the Al-Raith Road, Kingdom of Saudi Arabia, using remote sensing data and field investigations
}

\begin{abstract}
Jizan mountainous areas in Kingdom of Saudi Arabia are suffering from a variety of slope failures. Most of these failures happen due to heavy rainfalls from time to time. These landslides include rock topples, rockslides, debris flow, and some combination of these which affected many roads, highways, and buildings. The Al-Raith Road is one of these roads connecting Red Sea coast cities with Asir and Al-Hasher areas. The length of this road reaches about $45 \mathrm{~km}$ and it has been exposed to landslides during each heavy rain storm. One of these events happened in 24 August 2013, which caused huge debris flows that cut and damaged the road. The current research aims to evaluate the debris flow assessment along this highway using remote sensing data and field studies. According to the detailed analysis of geological and geomorphological maps, as well as field investigation, it is evident that the debris flow materials are mainly related to the different types of landslides. These landslides included rock topples which are frequently observed along the side walls of the channels (flexture which occur in foliated rocks and block which occurs in massive rocks), rock sliding (planner failures) where many rock joints and shear zones dip towards the channel, and rockfalls. Debris range in their size from up to $2 \mathrm{~m}$ in diameter to fine materials less than 2 $\mathrm{mm}$. These materials can be easily moved with water causing a risk to vehicles, roads, and housing in the area. Field study indicated that these debris channels especially at the lower part have been reactivated several times in the past. Finally, suitable solutions have been suggested to these critical sites to minimize and/or avoid the debris flow hazards in the future.
\end{abstract}

Keyword: Debris flow; Remote sensing data; Field investigations; Landslides 